\title{
AUTENTICIDADE E INTERMIDIALIDADE NOS LIVROS ILUMINADOS DE WILLIAM BLAKE: UM IMPASSE PARA A TRADUÇÃO ${ }^{1}$
}

\author{
Juliana Steil ${ }^{1}$ \\ 1 Universidade Federal de Pelotas, Pelotas, Rio Grande do Sul, Brasil
}

\begin{abstract}
Resumo: Este artigo examina como as traduções da obra de William Blake para a língua portuguesa tratam a materialidade visual dos livros iluminados do autor. Nesse sentido, são discutidas soluções apresentadas em traduções como "A rosa doente" (tradução de Augusto de Campos, Viva Vaia, 1979) e Jerusalém (tradução de Saulo Alencastre, Cânone Gráfico, 2015).
\end{abstract}

Palavras-chave: William Blake; Intermidialidade; "A rosa doente"; Jerusalém; Gilberto Sorbini \& Weimar de Carvalho; Manuel Portela; Saulo Alencastre; Augusto de Campos

\section{AUTHENTICITY AND INTERMEDIALITY IN WILLIAM BLAKE'S ILLUMINATED BOOKS: A TRANSLATORIAL IMPASSE}

\begin{abstract}
This paper looks at how translations of William Blake into Portuguese treat the visual materiality of his illuminated books. It will assess the translatorial solutions used in Jerusalém (translated by Saulo
\end{abstract}

\footnotetext{
1 A primeira versão deste trabalho foi apresentada no II Colóquio Poesia e Tradução (POET-UFC / Casa Guilherme de Almeida), realizado na Universidade Federal do Ceará em novembro de 2017. Meus agradecimentos a Juliet Attwater pela tradução do resumo para o inglês, a Érico Assis pela notícia da publicação do excerto de Jerusalém no segundo volume de Cânone Gráfico (Kick) e pelo acesso à obra, e a Bibiana Leme, da editora Boitempo, pelo envio da imagem (Kick, 98) incluída neste artigo.
} 
Alencastre, Cânone Gráfico, 2015) and "A rosa doente" (translated by Augusto de Campos, Viva Vaia, 1979), among other translations.

Keywords: William Blake; Intermediality; "The Sick Rose"; Jerusalem; Gilberto Sorbini \& Weimar de Carvalho; Manuel Portela; Saulo Alencastre; Augusto de Campos

A materialidade dos livros iluminados de William Blake (17571827) e a edição destas obras são assuntos que têm recebido reiterada atenção de pesquisadores da área de literatura. A partir de um ponto de vista parecido com o de Manuel Portela (2015), este trabalho pretende verificar como as traduções da obra de Blake, para a língua portuguesa em particular, têm procedido no que se refere ao caráter visual dos livros proféticos do artista. Antes de examinar algumas traduções, será necessário descrever brevemente a configuração híbrida e autógrafa ${ }^{2}$ desses livros, procurando mostrar um pouco da contribuição de sua forma verbo-visual para o projeto poético do autor. Certamente, esta configuração serve a diferentes propósitos poéticos, por assim dizer, mas importa destacar, aqui, o argumento de que ela ajuda a expressar a defesa da criatividade artística do indivíduo como afirmação da infinitude da Imaginação e como caminho para o retorno ao organismo coletivo do Homem Universal. Esta é uma preocupação central na obra de Blake. No caso da configuração dos livros proféticos, esta ênfase sobre a criatividade individual tem uma relação específica com circunstâncias históricas.

Nesse ponto, é preciso lembrar que Blake era um gravurista de profissão no centro da Revolução Industrial. Para Jacob Bronowski, autor de William Blake and the Age of Revolution, Blake é o poeta cuja vida e obra expressam de modo mais sensível as mudanças desta época, que se dirigia a uma experiência social mais desumana e mais mecânica, por causa das guerras - lembrando que o Reino Unido esteve envolvido em várias delas nesse tempo, incluindo

\footnotetext{
${ }^{2}$ Neste artigo, utilizo o termo "autógrafo", bem como o termo “remediação", em referência ao artigo de Portela (2015).
}

Cad. Trad., Florianópolis, v. 39, no 2, p. 32-47, mai-ago, 2019. 
a Guerra dos Sete Anos (1756-1763), a Guerra da Independência dos Estados Unidos (1775-1783) e as Guerras Napoleônicas (18031815) -, e por causa da transição dos modos de produção artesanal para os modos de produção com o uso das máquinas na fábrica.

Makdisi (86), em William Blake and the impossible history of the 1790s, chama atenção para o fato de Charles Babbage (17911871), um dos primeiros grandes teóricos da montagem moderna, encontrar na profissão de Blake, a gravura em metal, um modelo conceitual da fábrica moderna ${ }^{3}$. Em seu livro publicado em 1832, On the economy of machinery and manufactures, Babbage realiza uma espécie de investigação operacional com o objetivo de "apontar os efeitos e as vantagens que surgem do uso de ferramentas e máquinas (...)"4 (Babbage 01). O capítulo XI deste livro é dedicado ao princípio "Da Cópia”, que seria, segundo ele, fundamental para a qualidade uniforme do trabalho produzido pela máquina e para o baixo custo dos artigos produzidos por ela (Babbage 51). Para explicar o princípio da cópia, o capítulo descreve uma série de modalidades de gravação e impressão.

Para Babbage, a gravura em metal oferecia um arquétipo para o novo modo de produção, pois a placa gravada permitia a produção de um grande número de cópias teoricamente idênticas. O teórico nota, contudo, a desvantagem do longo tempo gasto pelo gravurista para produzir a placa-matriz. A fábrica eficiente exigia velocidade, e isso seria resolvido com a divisão do trabalho entre vários trabalhadores (Makdisi 146-147).

Como observa Makdisi, o princípio da divisão de trabalho para uma produção eficiente já se intensificava no trabalho do gravurista na época de Blake. Para o crítico, em função de sua experiência

\footnotetext{
${ }^{3}$ A discussão sobre a gravura como arquétipo da fábrica moderna e a descrição da técnica utilizada na criação dos livros proféticos iluminados de Blake foram apresentadas anteriormente em minha tese Tradução comentada de Milton de William Blake (2011), da qual transcrevo aqui alguns parágrafos, fazendo alguns ajustes.

4 "The object of the present volume is to point out the effects and the advantages which arise from the use of tools and machines". As traduções das citações indicadas em notas de rodapé são da autora do artigo.
}

Cad. Trad., Florianópolis, v. 39, n⿳0 2, p. 32-47, mai-ago, 2019. 
profissional como artesão-gravurista, Blake esteve em uma posição privilegiada para avaliar o modo da produção industrial moderna que vinha se estabelecendo em Londres no século XVIII:

primeiro porque [a gravura em metal] estava entre as primeiras formas de produção a implantar o que pode ser identificado como um processo industrial baseado na divisão do trabalho, e segundo (...) porque envolvia a reprodução da imagem, algo que está no coração da cultura capitalista moderna $^{5}$ (Makdisi 149-150).

$\mathrm{O}$ desconforto de Blake em relação à desvalorização do viés artístico do trabalho do gravurista pode ser percebido em seu Public Address:

as obras de Woolett \& Strange são [...] o Trabalho da Vida de artífices Ignorantes adequado para Fins de Comércio. Sem dúvida que o Comércio Não pode Suportar o Mérito Individual; sua Pança insaciável deve ser alimentada com O Que todos podem fazer Igualmente bem. Pelo menos é assim na Inglaterra, como tenho sentido na Pele estes Quarenta $\operatorname{Anos}^{6}$ (Erdman 572).

Para além da defesa da sua própria habilidade, esta passagem, deixada em seu caderno de rascunhos, mostra uma reação contra a

\footnotetext{
5 "first because it was among the earliest forms of production to deploy what can be recognized as an industrial process based on the division of labor, and second (...) because it was concerned with the reproduction of the image, which lies at the very heart of modern capitalist culture".

6 "Wooletts \& Stranges works are like those of Titian \& Correggio the Lifes Labour of Ignorant journeymen Suited to the Purposes of Commerce no doubt for Commerce Cannot endure Individual Merit its insatiable Maw must be fed by What all can do Equally well at least it is so in England as I have found to my Cost these Forty Years".
} 
subordinação do sujeito a um amplo esquema disciplinar, em que o artesão anula seu talento em favor de um desempenho comum e intercambiável, adequado ao fluxo de produção de bens de consumo. Essa crítica, segundo Makdisi, reflete-se fortemente no método que Blake desenvolveu para produzir seus "livros iluminados".

Enquanto que na composição de um livro de acordo com o método utilizado na época imagem e texto não podiam ser produzidas ao mesmo tempo ${ }^{7}$, a técnica inventada por Blake por volta de 1787 permitia unir os dois meios de expressão na mesma placa, de forma que imagem e texto pudessem ser impressos juntos em um mesmo lance da prensa. Ao invés de gravar sulcos na placa de metal para formar os traços do desenho, Blake desenhava as imagens e escrevia o texto (em espelho) na placa com um líquido resistente ao ácido, deixando o restante da placa - a parte que deveria aparecer em branco na página - exposto à ação da água-forte. Os traços criados na placa, assim, apareciam em alto relevo, justamente o contrário do que acontecia no método tradicional da gravura em metal. Depois que essa combinação de texto e imagem era impressa, a página era pintada à mão, com aquarela. Também era comum Blake acrescentar e excluir páginas, e até mesmo mudar a ordem das páginas nos exemplares de seus livros. Deste modo, Blake produzia exemplares únicos, isto é, nenhum exemplar poderia ser absolutamente idêntico a outro. Isto pode ser observado nas cópias existentes de qualquer livro iluminado do artista.

Para Makdisi, o método de composição utilizado por Blake, e as peças singulares que resultam desse método, são uma forma de subversão da lógica industrial representada na sua profissão de gravurista. Com esse processo de criação, Blake desestabiliza a relação hierárquica entre artista e artesão (no sentido de que o gravurista normalmente era considerado mero copista da obra artística alheia), criação e execução, original e cópia.

\footnotetext{
7 Segundo Bentley (101), várias tentativas de unir imagem e texto na mesma gravura já haviam sido feitas. As técnicas usadas para isto, porém, eram tão dispendiosas que se tornavam inviáveis. Já o método desenvolvido por Blake era mais rápido e econômico.
}

Cad. Trad., Florianópolis, v. 39, nº 2, p. 32-47, mai-ago, 2019. 
Nesse sentido, ao criar um modo de produzir originais autógrafos a partir das técnicas de reprodução de imagem mais avançadas da época, Blake estabelece uma espécie de inovação anacrônica procurando preservar a aura da obra de arte. Do ponto de vista de Portela (25), “Ao transformar cada exemplar numa edição, a técnica de William Blake reinscreve a reprodutibilidade técnica na presença autográfica da mão do escritor e da mão do pintor".

A técnica e a natureza "intermidial" dos livros proféticos iluminados, em que o texto visual e o texto literário são inseparáveis, oferecem determinadas dificuldades para a sua edição posterior, sendo que esta edição posterior significa, em sua forma tradicional, "usar um livro para representar outro livro" (Portela 16). No caso da tradução interlingual dos livros proféticos, estas dificuldades ficam ainda mais evidentes, já que o texto literário original está fixado na textualidade visual dessas obras.

Considerando estas questões, remontar a máquina da criação (Campos, H.) do livro profético exigirá que sejam resolvidos dois princípios de resistência que eles apresentam à tradução:

1. a autenticidade da obra em cada exemplar;

2. a sua intermidialidade.

A autenticidade do livro profético o torna resistente à tradução por causa do seu "aqui e agora" como obra de arte, da "existência única” (Benjamin 167) de cada um de seus exemplares, que se fundamenta na presença da mão do artista em sua materialidade.

A intermidialidade, por sua vez, ou a indissociabilidade entre texto visual e texto literário operada no livro profético, o torna resistente à tradução porque o aproveitamento do texto literário separadamente desmonta a sua máquina criativa.

As traduções em língua portuguesa têm apresentado diferentes abordagens das questões de autencidade e de intermidialidade dos livros proféticos. A mais frequente é aquela adotada, por exemplo, na tradução de Gilberto Sorbini \& Weimar de Carvalho: 
Figura 1: Blake 106-107b

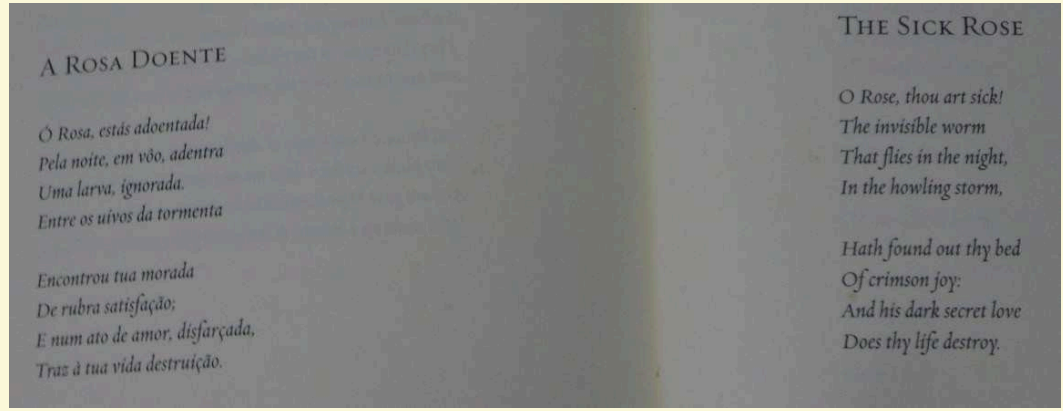

Fonte: arquivo pessoal

"The Sick Rose", como sabemos, faz parte do conjunto de poemas publicados em Songs of Innocence and of Experience, cujos exemplares apresentam diferentes configurações nas impressões feitas desde 1794, aproximadamente, até 1827 (Eaves, Essick and Viscomi).

Este conciso poema dá espaço a muitas interpretações, e a de Robert Essick é uma das mais aceitas. Essick afirma que no século 18 se acreditava que uma variedade de doenças era propagada pelo ar à noite; assim, "o verme que ataca rosas é uma metáfora para os agentes invisíveis que causam as doenças. A 'tormenta uivante' seria uma metáfora para a paixão sexual, e nesse caso Blake estaria fazendo referência às doenças sexualmente transmissíveis" (Blake 121d). Além disso, ainda segundo a leitura de Essick, "o ciúme é normalmente representado pela imagem de um verme, e, assim, a poluição do amor pode ser ao mesmo tempo psicológica e física. O ciúme destrói o amor; a doença destrói a 'vida'"9 (Blake 122d).

\footnotetext{
8 "The worm that attacks roses is a metaphor for the invisible agents that cause human ailments. The 'howling storm' may be a metaphor for sexual passion, and if so then Blake is referring specifically to sexual transmitted diseases".

9 "Jealousy is conventionally imaged as a worm, and thus the pollution of love may be as much psychological as physiological. Jealousy destroys love; diseases destroys 'life"'.
}

Cad. Trad., Florianópolis, v. 39, no 2, p. 32-47, mai-ago, 2019. 
Mas o poema também pode indicar uma "ressonância histórica" mais específica, como observa Diniz, apontando a leitura do crítico Jon Mee. Para Mee, citado por Diniz (77), “The Sick Rose” tem ligação com dois poemas satíricos, publicados em um jornal radical na época, que criticavam "o jornalista George Rose, um dos secretários do Tesouro que, por volta de 1790, foi acusado de 'subsidiar jornais, empregar escritores, distribuir panfletos e comprar votos, tudo com dinheiro do tesouro' (MEE)". A rosa dos poemas do The Argus está podre por causa da corrupção" (Diniz 77). Assim, "a Rosa [numa alusão a George Rose] seria o primeiro signo da corrupção dos tempos da política. O envolvimento do jornalista na manipulação eleitoral era visto como um câncer que minava a tradição de liberdade inglesa" (Diniz 77).

Seja qual for a interpretação, o conteúdo visual do poema certamente não é um mero suplemento para o texto, mas "estabelece um diálogo com o poema, ora explicitando o que está apenas implícito no texto, ora acrescentando dimensões de sentido e possibilidades interpretativas", como argumenta Sérgio Bellei em Hipertexto e literatura. Bellei observa que, em "The Sick Rose",

\begin{abstract}
A dimensão da mortalidade humana, apenas sugerida no texto, torna-se visualmente explicitada nas figuras femininas. E o verme destruidor apresenta-se, de forma mais específica, como uma lagarta roedora (...). Mas o detalhe ilustrativo de maior significado é a rosa que, apresentada no texto como "doente", apresenta-se visualmente em plena florescência. (...). O que a ilustração diz é que a rosa está doente, precisamente, em seu momento mais intenso de vida, beleza e plenitude (Bellei 106-107b).
\end{abstract}

A comparação das reproduções das páginas de diferentes exemplares dá uma ideia mais aproximada da concepção visual da obra 
de Blake e dos princípios de autenticidade e de intermidialidade inerentes aos originais impressos pelo autor ${ }^{10}$.

Nota-se que a tradução de Gilberto Sorbini e Weimar de Carvalho objetiva refazer o texto poético, mas não faz parte de sua proposta fazer qualquer tentativa de remediar a sua textualidade visual. A apresentação do texto transcrito e atualizado a um novo padrão de edição não deixa de promover a divisão entre Blake-poeta e Blake-pintor, o que é uma prática frequente na história editorial da obra de Blake. Portela (23) comenta que

A divisão entre Blake-poeta e Blake-pintor decorreria das limitações da própria tecnologia de impressão para reproduzir integralmente as impressões iluminadas, que levaram a que o texto dos poemas fosse transcrito e publicado separadamente. Esta divisão tecnológica foi, por seu turno, reforçada por divisões disciplinares e institucionais de produção de conhecimento fundadas na separação entre texto e imagem. A dissociação entre impressão-texto e iluminura-imagem teria resultado de um processo histórico de reprodução mecânica e institucional da obra, que separou e hierarquizou o que estava material e simbolicamente integrado.

Buscando mostrar a natureza intermidial da obra, a solução apresentada na tradução de Manuel Portela é utilizar a reprodução da página original:

\footnotetext{
${ }^{10}$ Em The William Blake Archive (Eaves, Essick and Viscomi: < http://www. blakearchive.org >), é possível visualizar a comparação de vários exemplares ou cópias de determinada página ou pintura; para comparar as diferentes imagens de "The Sick Rose" deve-se selecionar a página do poema em um dos exemplares de Songs of Innocence and of Experience disponíveis no portal (o exemplar B, por exemplo: < http://www.blakearchive.org/copy/songsie.b?descId=songsie.b.illb k.44>) e clicar na guia "Object from the Same Matrix".
} 
Figura 2: Blake 130-131c

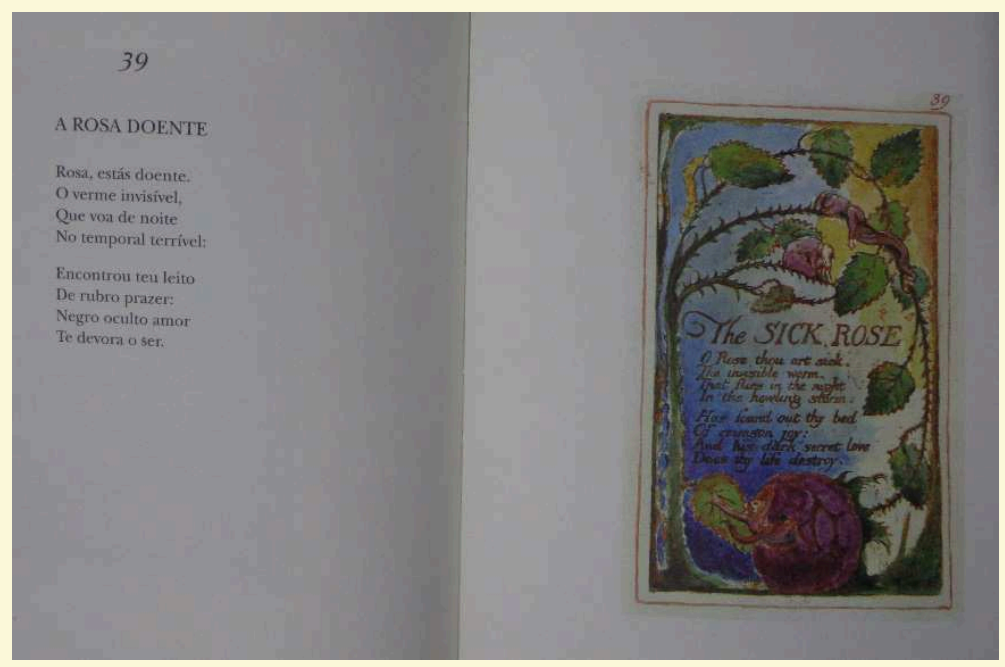

Fonte: arquivo pessoal

A estratégia da editora Antígona dá continuidade a uma prática editorial impressa recente que, como observa Portela, "ao longo do século $\mathrm{XX}$, integrara a obra de William Blake na lógica geral de reprodução da imagem, fazendo com que uma cópia de um livro iluminado valesse por todas as restantes" (Portela 26). Dos cerca de 55 exemplares originais de Songs of Innocence and of Experience existentes, o que foi reproduzido na edição da Antígona é precisamente o exemplar de 1826 que hoje faz parte do acervo da coleção de livros raros da Biblioteca do Congresso.

Como ressalta Benjamin (177), "o objeto reproduzido é uma obra de arte, e a reprodução não o é"; nesse sentido, a reprodução fac-similada cumpre a função de aproximar do leitor o original autógrafo. Vale notar que a tradução de Portela propriamente dita não propõe representar a textualidade visual, dividindo a experiência de fruição do visual e do literário e se ocupando do texto literário apenas. 
De outro lado, algumas alternativas têm sido experimentadas no sentido de reintegrar na tradução o texto visual e o texto literário, como se vê, por exemplo, no caso do trabalho com a tradução de Saulo Alencastre:

Figura 3: penúltima imagem de Jerusalém

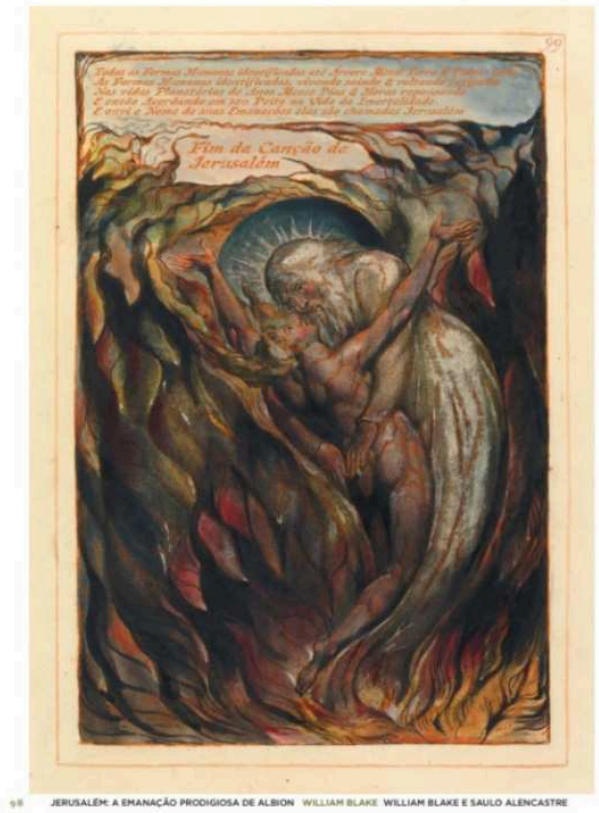

Fonte: (Kick 95)

Esta imagem representa a penúltima das cem páginas de Jerusalem, o mais longo dos livros proféticos editados por Blake na técnica iluminada. Como sintetiza a apresentação em The William Blake Archive (Eaves, Essick and Viscomi), Jerusalém constitui uma recapitulação dos múltiplos interesses do artista, 
desde sua própria mitologia até a história bíblica, da sexualidade à epistemologia, e dos druidas a Newton. O conjunto de personagens é vasto, mas os papeis principais são representados por Los (a imaginação do artista em ação no mundo material), Jerusalém e Álbion (as porções feminina e masculina da humanidade dividida que deve ser reunida), a deusa da natureza Vala e Jesus. (...) Jerusalém conclui com uma visão da consciência humana em um universo pósapocalíptico ${ }^{11}$.

Nesta sugestiva imagem, o casal provavelmente representa Álbion, o mítico gigante inglês, e sua emanação Jerusalém, que é, para Blake, a Visão Divina e a Liberdade (Eaves, Essick and Viscomi). A leitura da imagem leva a pensar sobre o sentido simbólico da aparência e dos gestos das personagens envoltos no cenário flamante.

A página traduzida mostrada aqui faz parte de uma seleção de seis páginas de Jerusalém incluídas no volume 2 de Cânone Gráfico - Clássicos da literatura universal em quadrinhos, antologia "organizada pelo escritor Russ Kick e lançada originalmente nos Estados Unidos em 2012” (Boitempo). A antologia propõe, de acordo com a editora, reunir "o melhor da literatura de todos os tempos em adaptações feitas por talentosos artistas visuais" (Boitempo). Nesta antologia, dirigida "para aqueles que se interessam por quadrinhos" (Boitempo), Jerusalém aparece como reprodução da realização gráfica original. Nesta edição brasileira, o texto em inglês é então substituído pela tradução de Alencastre $^{12}$. Fica re-

11 "ranging from his own mythology to biblical history, from sexuality to epistemology, and from the Druids to Newton. The cast of characters is vast, but Los (the artist's imagination at work in the material world), Jerusalem and Albion (the female and male portions of divided humanity who must be reunited), the nature goddess Vala, and Jesus play major roles. (...) Jerusalem concludes with a vision of human consciousness in a post-apocalyptic universe".

${ }^{12}$ A tradução de Alencastre é apresentada nesta configuração, com letreiramento realizado por Lilian Mitsunaga, somente nas seis páginas selecionadas em Cânone Gráfico II; a edição que traz a tradução integral, publicada pela editora Hedra em 2010, não contém imagens das gravuras.

Cad. Trad., Florianópolis, v. 39, nº 2, p. 32-47, mai-ago, 2019. 
mediada, assim, a questão da intermidialidade da página de Blake, gerando a possibilidade de fruição da tradução como textualidade composta de texto visual e texto literário. Segue sem solução, contudo, o problema da autenticidade da página profética.

Finalmente, a tradução de Augusto de Campos para "The Sick Rose" - ou "intradução", como ele a chama (Campos, A.) -, se for comparada ao original, elabora de outro modo as questões de autenticidade e intermidialidade:

Figura 4: A Rosa Doente
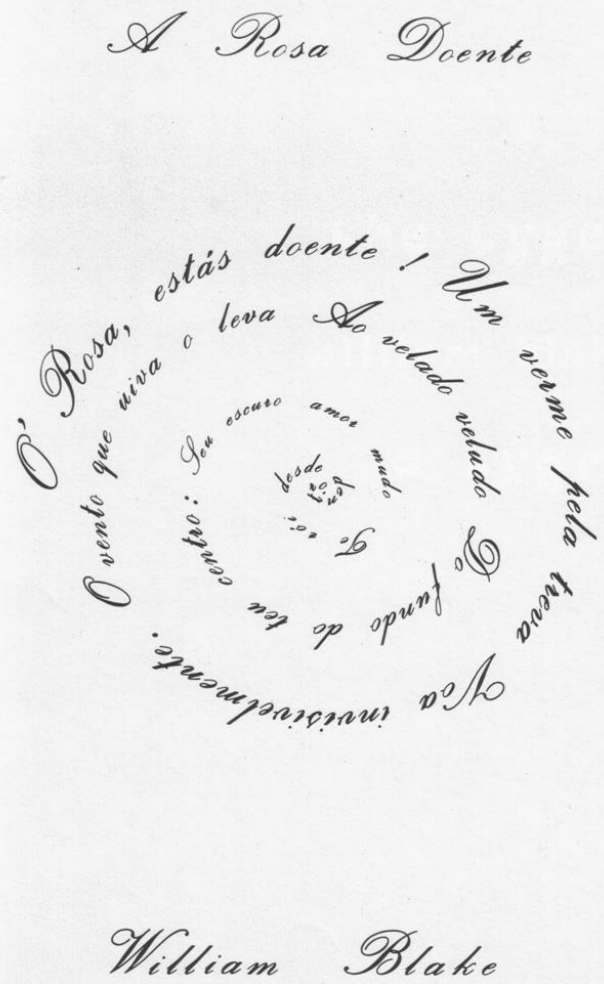

Fonte: (<https://escamandro.files.wordpress.com/2014/11/a-rosa-doente.jpg > . Acesso em: 20 maio 2018) 
O projeto de Augusto propõe uma completa atualização da máquina criativa. A forma dos versos em espiral alude à imagem de uma rosa, e o estilo da fonte imita a letra manuscrita. Existe aqui uma nova obra intermidial, pois ela integra o texto visual e o texto literário, por meio de recursos de edição e impressão contemporâneos. Embora haja ligação com o poema original, as novas condições de produção - que se utiliza da técnica de reprodutibilidade em alta escala -, por sua vez, reprimem a materialidade autógrafa original e, com ela, a sua mensagem crítica da lógica industrial e da padronização da criatividade.

Em última análise, todas as traduções mencionadas substituem a "existência única da obra por uma existência serial”, o que atrofia a aura da obra de arte, como diria Benjamin (168). De outro lado, a reprodução da obra realizada nessas traduções, especialmente nas traduções de Manuel Portela (Antígona) e de Saulo Alencastre (Barricada), é capaz de representar o original como presença virtual. Esta estratégia talvez provoque a idealização do original, paradoxalmente agindo em favor de sua aura.

\section{Referências}

Bellei, Sérgio. O livro, a Literatura e o Computador. São Paulo: EDUC / Florianópolis: UFSC, 2002.

Bellei, Sérgio Luiz Prado. Hipertexto e Literatura. Porto Alegre: EDIPUCRS, 2012.

Benjamin, Walter. "A Obra de Arte na Era de sua Reprodutibilidade Técnica". In: Benjamin, Walter. Magia e Técnica, Arte e Política: Ensaios Sobre Literatura e História da Cultura. Tradução de Sérgio Paulo Rouanet. São Paulo: Brasiliense, 1985. 
Blake, William. O Matrimônio do Céu e do Inferno / O Livro de Thel. Tradução de José Antônio Arantes. 4.ed. São Paulo: Iluminuras, 2001. (a)

Blake, William. Canções da Inocência e Canções da Experiência. Tradução de Gilberto Sorbini e Weimar de Carvalho. São Paulo: Disal, 2005. (b)

Blake, William. Cantigas da Inocência e da Experiência. Tradução de Manuel Portela. $2^{a}$ edição. Lisboa: Antígona, 2007. (c)

Blake, William. Songs of Innocence and of Experience. Edited, with a commentary, by Robert N. Essick. San Marino: Huntington Library, 2008. (d)

Boitempo. Cânone Gráfico II - Clássicos da Literatura Universal em Quadrinhos. 2018. 20/05/2018<https://www.boitempoeditorial.com.br/produto/canonegrafico-ii-549>.

Campos, Augusto de. Viva Vaia. São Paulo: Duas Cidades, 1979.

Campos, Haroldo de. "Da Tradução Como Criação e Como Crítica." In: Metalinguagem e Outras Metas: Ensaios de Teoria e Crítica Literária. São Paulo: Perspectiva, 2004.

Eaves, Morris; ESSICK, Robert N.; VISCOMI, Joseph. The William Blake Archive. 2018. 19/05/2018. < http://www.blakearchive.org >

Erdman, David V. The Complete Poetry \& Prose of William Blake. Newly revised edition. New York / London / Toronto / Sydney / Auckland: Anchor Books, 1988.

Kassab, Álvaro; GOMES, Eustáquio. Augusto de Campos. O 'Vocalista' da Alma e da Forma. 2018. Entrevista. Disponível em: < http://www.ubern.org.br/canal. php? $\operatorname{codigo}=508>$. Acesso em: 19 maio 2018 .

Kick, Russ (org.). Cânone Gráfico - Clássicos da Literatura Universal em Quadrinhos, v. 2: desde "Kublai Khan" até as Irmãs Brontë e O Retrato de Dorian Gray. São Paulo: Barricada, 2015. 
Makdisi, Saree. William Blake and the Impossible History of the 1790s. Chicago/ London: The University of Chicago Press, 2003.

Portela, Manuel. "Livros Iluminados Digitais: Autógrafo e Reprodução em The William Blake Archive.” Revista Letras, 51. Santa Maria: PPGL Editores, 2015.

Recebido em: 10/11/2018 Aceito em: 17/03/2019 Publicado em maio de 2019

Juliana Steil. E-mail: julianasteil@gmail.com. ORCID: https://orcid.org/00000002-7336-0299 